\title{
Application of Low-Phosphorous Fertilizers on Tea Plantations as a Novel Best Management Practice
}

\section{Chi-Feng Chen ${ }^{1, *}$, Chih-Yi Hu ${ }^{2}$, Ming-Lone Liou ${ }^{3}$, Chia-Chang $\mathrm{Wu}^{2}$, Yen-Shuo Su ${ }^{2}$ and Chien-Ju Liu ${ }^{2}$}

1 Department of Natural Resources, Chinese Culture University, Taipei City 11114, Taiwan

2 Wenshan Branch, Tea Research and Extension Station; New Taipei City 22391, Taiwan; E-Mails: chihyi@ttes.gov.tw (C.-Y.H.); tds311@ttes.gov.tw (C.-C.W.); tres561@ttes.gov.tw (Y.-S.S.); tres532@ttes.gov.tw (C.-J.L.)

3 Taipei Feitsui Reservoir Administration; New Taipei City 23160, Taiwan; E-Mail: mingloneliou@gmail.com

* Author to whom correspondence should be addressed; E-Mail: cqf2@faculty.pccu.edu.tw; Tel.: +886-2-2861-0511 (ext. 31432).

External Editor: Yu-Pin Lin

Received: 14 August 2014; in revised form: 28 September 2014 / Accepted: 28 September 2014 / Published: 7 October 2014

\begin{abstract}
Taipei Feitsui Reservoir supplies drinking water to more than five million citizens in northern Taiwan. The Feitsui Reservoir Administration and Tea Research and Extension Station have implemented a new pollution control measure for the use of low-phosphorous (low-P) fertilizers to prevent eutrophication. In this study, we compared the quality of the soil, effluent and tea from two test fields. Low-P fertilizer was applied to one of the fields, and regular phosphorous fertilizer (regular-P) was applied to the other. The study period covered spring and winter seasons. The results showed that the investigated soil chemical properties were not influenced by either the low-P or regular-P fertilizers. The effluent quality was influenced by the precondition of the soil, which resulted in a larger average total phosphorous (TP) concentration in the low-P field. However, there was a decreasing trend in $\mathrm{P}$ concentration that amounted to approximately half of the average TP concentration in the regular-P field. The growth characteristics and yields were not significantly different between the two fields, but the taste and aroma of the tea from the low-P field was rated as superior to that of the regular-P field.
\end{abstract}


Keywords: agricultural best management practices (BMPs); tea; fertilizers; phosphorous; water quality

\section{Introduction}

Agricultural fields may be regarded as nonpoint pollution sources, because their runoff may contain residual fertilizers and pesticides that negatively affect the quality of downstream water bodies. Fertilizers are necessary to ensure crop yields, but are often applied excessively. The excessive fertilizers remain on top of the soils and enter the groundwater through deep percolation, which results in environmental pollution. Alternative methods of fertilization and cultivation have been discussed to reduce the amount of residual fertilizers that are transported into waterbodies [1-5]. For example, Liu et al. [4] found that applied organic and low-release fertilizers can reduce the loss of nitrogen (N) and phosphorous (P) and maintain tea yields. Sainju et al. [2] suggested that cultivating a combination of legumes and non-legumes and reducing the use of $\mathrm{N}$ fertilizers can decrease the loss of soil $\mathrm{N}$ and benefit crop yields. Kim et al. [6] confirmed through model calculations that the application of excess fertilizers produces high levels of $\mathrm{N}$ and $\mathrm{P}$ in the runoff water.

The application of excess fertilizer can result in high nutrient loss. For this reason, numerous best management practices (BMPs) have been implemented to mitigate the detrimental effects of nutrient loss on soil and water. Traditional BMPs treat collected runoff pollutants as a whole, and specific BMPs for $\mathrm{N}$ or $\mathrm{P}$ have not been designed. However, some water bodies are affected by particular pollutants; therefore, a specific BMP might be more effective. The Feitsui Reservoir is located in northern Taiwan and supplies drinking water to five million people in Taipei City and New Taipei City, Taiwan. P concentrations are a major cause of concern for the water quality in the Feitsui Reservoir [7], and tea plantations are the one of main pollution sources. Zehetner et al. [8] analyzed sediments from the Feitsui Reservoir and tea soils and confirmed that tea plantations are the sources of $\mathrm{P}$ in the reservoir. Chang [9] sampled runoff from tea plantations and concluded that the $\mathrm{P}$ concentration in the runoff after fertilization could be up to three times greater than the concentration before fertilization. $\mathrm{Wu}[10]$ evaluated long-term water quality monitoring data and found that the total phosphorous (TP) and $\mathrm{NH}_{3}-\mathrm{N}$ concentrations were increased in areas proximal to intensive tea cultivation. Tea cultivation has been the traditional economic activity in the Feitsui watershed, even before construction of the reservoir. Many BMPs that include structural and nonstructural measures have been implemented to reduce nonpoint pollution from tea plantations. In this study, we implemented a novel nonstructural BMP that was designed specifically for the control of $\mathrm{P}$.

Excessive $\mathrm{P}$ fertilization causes $\mathrm{P}$ to accumulate in the soil, and its residues then flow into bodies of water along with stormwater runoff [1]. Thus, the appropriate application of $\mathrm{P}$ fertilizer is an ideal BMP that may reduce the threat of excessive $\mathrm{P}$ concentrations and provide the required nutrients for tea cultivation. However, the process by which applied $\mathrm{P}$ is transformed and made available to the plants is complex, which makes it difficult to determine the optimal quantity of applied P. The available $\mathrm{P}$ for plants is derived from liquid and solid phases and involves biological and non-biological transformations [1,11]. Applied $\mathrm{P}$ changes the $\mathrm{P}$ stock in soils and influences the amount of $\mathrm{P}$ that is 
available for plants. Applied organic $\mathrm{P}$ helps to increase the available $\mathrm{P}$ in the topsoil and deeper soil layers. However, the excessive organic $\mathrm{P}$ might change soil texture and the adsorption capacity of soils, and reduced adsorption capacity and increased porosity may result in higher soil erosion and $\mathrm{P}$ loss, which increases the risk of water pollution.

Previous studies have suggested that the reduction or elimination of cultivation would help to fix $\mathrm{P}$ in the soil and reduce its loss [12,13]. Rational fertilizer application is also regarded as a BMP for nonpoint source pollution control. In this study, we introduced low-P fertilizers as a new BMP that is similar to the rational fertilizer method, but is specifically focused on the problem of excessive P. Traditional fertilizers were modified to include less than half of the usual amount of $\mathrm{P}$ and were then applied to the low-P field. The Taipei Feitsui Reservoir Administration and the Tea Research and Extension Station cooperated with the Taiwan Fertilizer Company to manufacture low-P fertilizers for tea cultivation. This study implemented low-P fertilizer and regular-P fertilizer treatments and monitored and compared the growth, yield and quality of tea plants, as well as the impact to soil and runoff.

\section{Methodology}

\subsection{Test Fields}

Wenshan Paochong tea is the most popular partially fermented tea in Taiwan, and it is produced in the northern mountainous areas of the Feitsui Reservoir watershed. Organic and chemical fertilizers are applied in this area, with chemical fertilizers predominating. Organic fertilizers are usually applied as the base fertilizer to improve the drainage and aeration of soil, but their nutrient content is low and must be transformed before the compounds are available. Chemical fertilizers contain high nutrient levels that are available for plant use; therefore, such fertilizers are usually applied to increase plant health and yield. The major elements of tea leaves are $\mathrm{N}, \mathrm{P}$ and potassium $(\mathrm{K})$, and the mass percentages are $4 \%$ to $6 \%, 0.25 \%$ to $0.40 \%$ and $1.5 \%$ to $2.1 \%$, respectively. Therefore, the most common fertilizer used for growing tea in the Feitsui watershed is the No. 1 compound fertilizer (Taiwan Fertilizer CO.,LTD., Taipei, Taiwan), which contains high $\mathrm{N}$ and $\mathrm{K}$ with $\mathrm{N}-\mathrm{P}_{2} \mathrm{O}_{5}-\mathrm{K}_{2} \mathrm{O}$ in a percentage of 20-5-10. In this study, a new low-P compound fertilizer was modified from the No. 1 compound fertilizer. The low-P compound fertilizer contains less than half of the $\mathrm{P}$ and has a percentage of 20-2.5-10 of N-P $\mathrm{P}_{2} \mathrm{O}_{5}-\mathrm{K}_{2} \mathrm{O}$. This fertilizer is still a trial product and is not in commercial production.

The test tea fields were located in the Wenshan Branch of the Tea Research and Extension Station in the reservoir watershed (Figure 1). The geographical features and weather conditions were the same for tea growth of the test fields, except the application of fertilizers. The tea variety was TTES (Taiwan Tea Experiment Station) No. 12, which is the second most common tea cultivar in Taiwan, and the tea trees in these fields are 28 years old. For effluent-water quality analysis, two individual test tea fields with 0.15 ha each at different elevations were chosen in order to prevent effluent mixing, and 150 kilograms of fertilizer were applied to each test field in July. For another test for comparing qualities and yields of tea between two fertilizer treatments, the test field was at the same elevation. A completely randomized design (CRD) was followed in the test field, and there were three small sampling zones with an area of 0.008 ha each and three replicates of each small zone. The tea harvest 
seasons in the watershed are spring and winter, which are the best seasons for manufacturing the partially fermented tea that is known as Paochong tea. Therefore, we applied fertilizer in mid-February before the spring harvest and in early September before the winter harvest. Nine kilograms of fertilizer were applied to each test field in each harvest season.

Figure 1. Photographs of the tested tea fields located in the Wenshan Branch, Tea Research and Extension Station, Shiding, New Taipei City. (a) The test tea fields at different elevations for effluent-water quality analysis. The upper field was for the application of low-P fertilizer, and the lower field was for regular-P fertilizer. (b) The test tea field at the same elevation for comparing tea qualities and yields between two fertilizer treatments. A completely randomized design (CRD) was utilized for the field test design, and three small zones were defined.

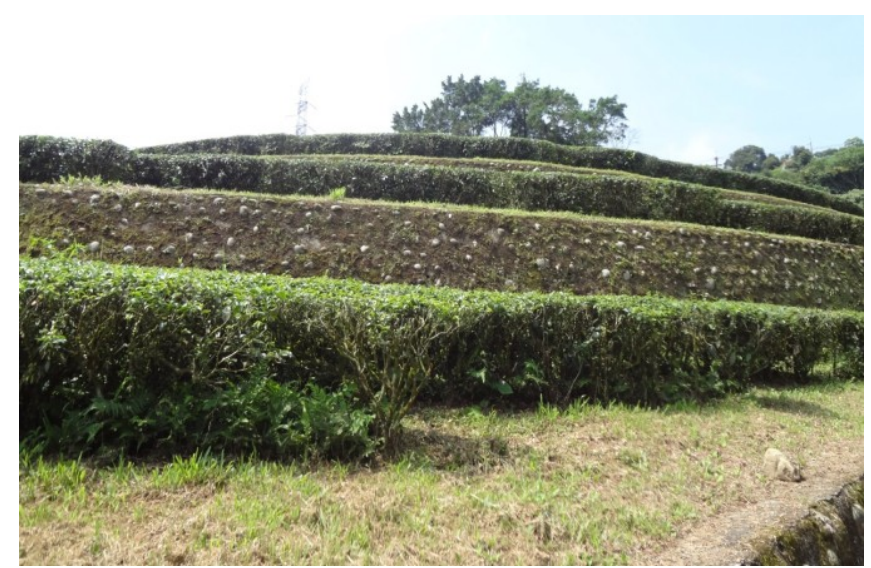

(a)

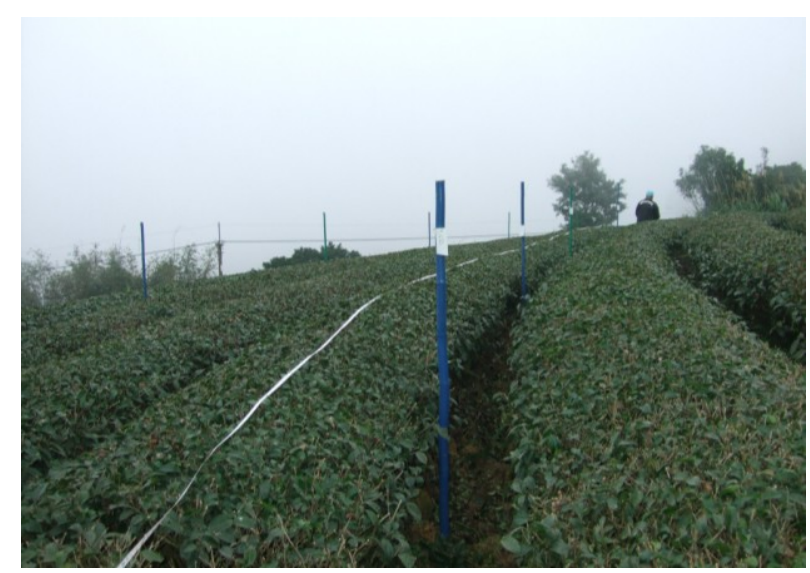

(b)

\subsection{Analyses}

\subsubsection{Soil Analysis}

Soils were sampled twice in each harvest season, with one sampling conducted prior to fertilization to characterize the baseline soil condition and the other sampling conducted prior to tea harvest to investigate the influence of fertilizers on some soil chemical properties. There were 50-60 days between fertilization and harvest. A total of four soil samplings were conducted in each test field, which included samplings during fertilization and harvest in the two seasons. Each sampling was conducted in three small zones, and there were three replicates for each zone. The topsoil at a depth of less than $20 \mathrm{~cm}$ and the bottom soil at a depth of $20 \mathrm{~cm}$ to $40 \mathrm{~cm}$ were tested, and the acidity, organic matter content and available elements, such as $\mathrm{P}, \mathrm{K}$, calcium $(\mathrm{Ca})$ and magnesium $(\mathrm{Mg})$, were analyzed.

The soil $\mathrm{pH}$ was determined using a 1:1 (V/V) soil/water mixture and measured with a Consort C861 multi-parameter analyzer (Consort bvba, Turnhout, Belgium) that included a Schott BlueLine 19 $\mathrm{pH}$ electrode. The $\mathrm{pH}$ electrode was calibrated with $\mathrm{pH}$ buffers at $\mathrm{pH} 4$ and 7 . For the organic matter tests, a 10-gram volumetric scoop of soil was placed into a crucible, dried for $6 \mathrm{~h}$ at $105^{\circ} \mathrm{C}$ and then weighed. The sample was then ashed for $16 \mathrm{~h}$ at $375^{\circ} \mathrm{C}$ and reweighed. The resulting weight loss, which was expressed as the percentage of the dry soil, was the estimate of organic matter content. The Bray-1 extractable phosphorus was extracted by shaking $2 \mathrm{~g}$ of air-dried soil in $20 \mathrm{~mL}$ of $0.025 \mathrm{M}$ 
$\mathrm{HCl}$ and $0.03 \mathrm{M} \mathrm{NH}_{4} \mathrm{~F}$ for $5 \mathrm{~min}$. The $\mathrm{P}$ content was determined from the filtrate according to the molybdate-blue method using ascorbic acid as the reductant. The color development was measured at $882 \mathrm{~nm}$ using a JASCO V-500 probe colorimeter. The base cations, including exchangeable $\mathrm{Ca}, \mathrm{K}$ and $\mathrm{Mg}$, were extracted by shaking $5 \mathrm{~g}$ of air-dried soil in $50 \mathrm{~mL}$ of $1 \mathrm{M} \mathrm{NH}_{4} \mathrm{OAc}(\mathrm{pH} 7)$ for $30 \mathrm{~min}$. The extracts were then centrifuged, and the supernatant was decanted and analyzed by inductively coupled plasma atomic emission spectroscopy (ICP-AES, Optima 2000 DV, ICP Optical Emission, Perkin Elmer, USA) [14,15].

\subsubsection{Water Quality Analysis}

We intended to collect the runoff to assess the fertilizers' effects on the water quality; however, the existing fields were flat and without open drainage channels, which is shown in Figure 1. The underground drainage pipes that were installed in the flat tea fields to release soil water were used to collect the effluent from the tea plantations. The groundwater drainage pipes were located at a $90-\mathrm{cm}$ depth under the field, and it was assumed that their filtration was comparable. All of the underdrain pipes were connected to the outside to release excess soil water. Figure 2 shows the water sampling bottles, and several sampling bottles were installed in each field to collect the effluents, which were mixed and refrigerated for later analysis. The analysis of water quality included evaluations of temperature, dissolved oxygen (DO), $\mathrm{pH}$, conductivity, total dissolved solids (TDS), suspended solids (SS), chemical oxygen demand (COD), total Kjeldahl nitrogen (TKN), nitrate nitrogen $\left(\mathrm{NO}_{3}-\mathrm{N}\right)$, nitrite nitrogen $\left(\mathrm{NO}_{2}-\mathrm{N}\right)$ and TP. The preserved water was sent to Taiwan SGS (Geneva, Switzerland) for water quality analysis.

Figure 2. Effluents from tea plantations were collected in sampling bottles and preserved for subsequent water quality analysis.
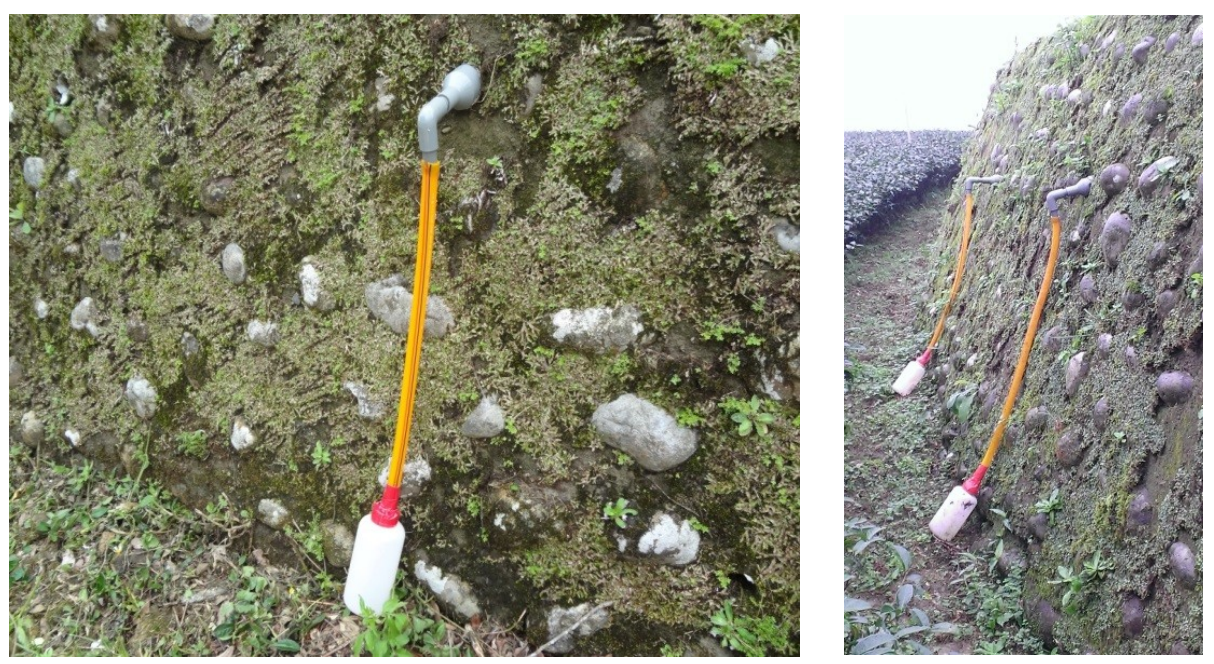

Water quality monitoring began in June and was completed at the end of November. Unfortunately, 2013 was a dry year, and there was below-average rainfall in this area until August. In mid-July, Typhoon Suli brought abundant rainfall and provided the water content for the soil; however, there was no production of effluent, even during the typhoon. The rainfall records are shown in Figure 3. The first effluent was produced after the soils became saturated at the end of August. Table 1 summarizes 
the sampling of the tea field effluents. The two test fields were designated as regular-P and low-P sites, and six effluent samples were collected for the regular-P site, although two had insufficient water volume for all of the water quality analyses. Four effluent samples were collected at the low-P site.

Figure 3. Rainfall hyetograph of the effluent experiments from June to November 2013.

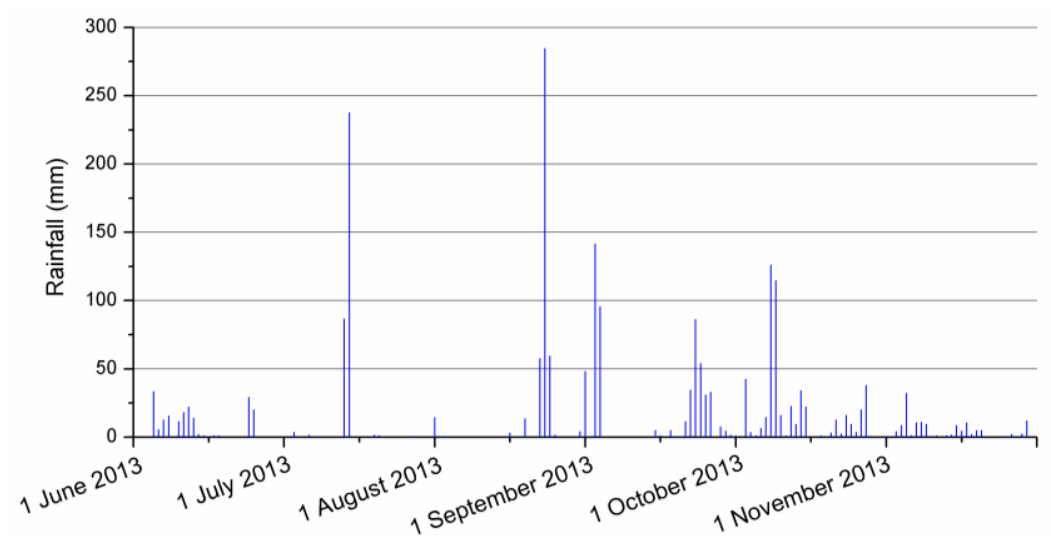

Table 1. Effluent sampling events.

\begin{tabular}{cccc}
\hline Date & Rainfall $(\mathbf{m m})$ & Regular-P site & Low-P site \\
\hline 29 August 2013 & 48 & Partial & Yes \\
31 August 2013 & 141.5 & Yes & Yes \\
21 September 2013 & 54 & Partial $*$ & Yes \\
6 October 2013 & 114.5 & Yes & Yes \\
24 October 2013 & 38 & Yes & No \\
13 November 2013 & 23.5 & Yes & No \\
\hline
\end{tabular}

* Note: Effluents were sampled, but the collected water volume was not sufficient for all of the water quality tests.

\subsubsection{Tea Analysis}

Fresh tea leaves and processed tea were analyzed, and the appearance and intrinsic properties of the fresh tea leaves were evaluated. The tea leaves were harvested in the designated small sampling zones, and there were three replicates for each zone. Ten tea leaves were collected from each replicate for evaluation. The length, width, thickness and the length of the second internode of each fresh tea leaf was measured, and the tea yield was calculated by the number of available harvested tea leaves that were collected within a $30 \times 30-\mathrm{cm}^{2}$ sampling frame and the weight of 100 tea buds. The harvested tea leaves were also tested for their element contents, including $\mathrm{P}, \mathrm{K}, \mathrm{Ca}$ and $\mathrm{Mg}$, to determine the tea quality. These elements were determined from $0.4 \mathrm{~g}$ of dried leaves digested in $10 \mathrm{~mL}$ of $98 \% \mathrm{H}_{2} \mathrm{SO}_{4}$ using the modification of Bremner (1965) [16] and analyzed by ICP-AES (Optima 2000 DV, ICP Optical Emission, Perkin Elmer, USA).

We also manufactured the tea to determine if the low-P fertilizers influenced the quality of the product. The tea buds from the two test fields were manufactured by the same process, and the quality of the tea was examined by sensory evaluation and chemical analysis. The tea sensory evaluation followed standard processes and criteria. Three reviewers participated in a blind taste test and graded the tea. Out of a total score of 100, 20 points represented tea appearance, 20 points represented the color of the liquid, 30 points represented the aroma and 30 points represented the taste. For the 
chemical analysis, $0.5 \mathrm{~g}$ of the dried tea samples were extracted with $10 \mathrm{~mL}$ of double-deionized water at $80{ }^{\circ} \mathrm{C}$ for $30 \mathrm{~min}$. The supernatant was collected and diluted with $100 \mathrm{~mL}$ of double-deionized water. The extract was then filtered through a $0.45-\mathrm{nm}$ polyvinylidene fluoride (PVDF) filter and injected into a high-performance liquid chromatography (HPLC) system (1200 series, Agilent, USA) to detect the theanine, caffeine, catechin (epigallocatechin gallate, EGCG) and total catechin content.

\section{Results and Discussion}

\subsection{Soil Quality}

The soil fertility in the spring and winter seasons is summarized in Tables 2 and 3, respectively. The soil was sampled during the harvest seasons, and the samples demonstrate the effects of the different fertilizers on the soil. We also tested the soil fertility before fertilization to characterize the original soil status. The soil quality was similar in both test fields before fertilization, because the two test fields were located in the same area and subject to the same environmental conditions. Therefore, we will only discuss the difference in soil quality during the harvest seasons.

Table 2. Soil fertility in the spring harvest season.

\begin{tabular}{|c|c|c|c|c|c|c|}
\hline Treatment & $\begin{array}{c}\text { pH } \\
(1: 1)\end{array}$ & $\begin{array}{c}\text { Organic } \\
\text { matter }(\mathrm{OM}) \\
(\mathrm{g} / \mathrm{kg})\end{array}$ & $\begin{array}{l}\text { Bray-1 P } \\
(\mathrm{mg} / \mathrm{kg})\end{array}$ & $\begin{array}{c}\text { Extractable K } \\
(\mathrm{mg} / \mathrm{kg})\end{array}$ & $\begin{array}{c}\text { Extractable Ca } \\
(\mathrm{mg} / \mathrm{kg})\end{array}$ & $\begin{array}{c}\text { Extractable Mg } \\
(\mathrm{mg} / \mathrm{kg})\end{array}$ \\
\hline \multicolumn{7}{|l|}{ Regular-P } \\
\hline Topsoil & $4.01 \pm 0.16$ & $91.2 \pm 8.2$ & $776.3 \pm 178.2$ & $269.8 \pm 27.2$ & $504.1 \pm 116.0$ & $32.4 \pm 7.6$ \\
\hline Bottom soil & $4.26 \pm 0.10$ & $65.7 \pm 5.0$ & $400.2 \pm 133.2$ & $108.4 \pm 11.5$ & $414.8 \pm 44.7$ & $36.7 \pm 3.5$ \\
\hline \multicolumn{7}{|l|}{ Low-P } \\
\hline Topsoil & $4.35 \pm 0.07$ & $99.9 \pm 4.4$ & $920.6 \pm 78.5$ & $221.1 \pm 12.7$ & $465.9 \pm 86.9$ & $41.2 \pm 9.2$ \\
\hline Bottom soil & $4.39 \pm 0.16$ & $59.4 \pm 1.7$ & $681.4 \pm 65.0$ & $157.5 \pm 9.4$ & $373.3 \pm 53.3$ & $39.7 \pm 5.3$ \\
\hline
\end{tabular}

Note: Mean \pm standard deviation.

Table 3. Soil fertility in the winter harvest season.

\begin{tabular}{|c|c|c|c|c|c|c|}
\hline Treatment & $\begin{array}{c}\text { pH } \\
(1: 1)\end{array}$ & $\begin{array}{c}\text { OM } \\
(\mathrm{g} / \mathrm{kg})\end{array}$ & $\begin{array}{c}\text { Bray-1 P } \\
(\mathrm{mg} / \mathrm{kg})\end{array}$ & $\begin{array}{c}\text { Extractable K } \\
(\mathrm{mg} / \mathrm{kg})\end{array}$ & $\begin{array}{c}\text { Extractable Ca } \\
(\mathrm{mg} / \mathrm{kg})\end{array}$ & $\begin{array}{c}\text { Extractable Mg } \\
(\mathrm{mg} / \mathrm{kg})\end{array}$ \\
\hline \multicolumn{7}{|l|}{ Regular-P } \\
\hline Topsoil & $3.64 \pm 0.14$ & $65.0 \pm 6.2$ & $526.8 \pm 195.3$ & $201.7 \pm 13.1$ & $525.9 \pm 150.1$ & $32.0 \pm 7.3$ \\
\hline Bottom soil & $3.66 \pm 0.08$ & $34.5 \pm 1.4$ & $192.5 \pm 156.9$ & $130.0 \pm 11.8$ & $203.6 \pm 10.4$ & $18.0 \pm 2.5$ \\
\hline \multicolumn{7}{|l|}{ Low-P } \\
\hline Topsoil & $3.55 \pm 0.04$ & $76.7 \pm 9.9$ & $454.3 \pm 164.4$ & $216.3 \pm 3.78$ & $373.3 \pm 52.3$ & $28.9 \pm 3.6$ \\
\hline Bottom soil & $3.73 \pm 0.03$ & $32.7 \pm 3.4$ & $231.0 \pm 96.1$ & $139.2 \pm 3.3$ & $259.4 \pm 26.3$ & $24.3 \pm 2.4$ \\
\hline
\end{tabular}

Note: Mean \pm standard deviation.

The spring season soil samples were collected in April, and they showed that the soil acidity was moderate and the organic matter was increasing, especially in the topsoil. The increase in organic matter resulted from plowing the topsoil and incorporating the pruned leaves. The available $\mathrm{P}$ in the soil had increased in both fields, and the concentration was higher in the low-P field than in the 
regular-P field. Both sites had already been rich in available $\mathrm{P}$ before fertilization, with the average available $\mathrm{P}$ in the topsoil of the low-P site at $669 \mathrm{mg} / \mathrm{kg}$ and the regular-P site at $579 \mathrm{mg} / \mathrm{kg}$. Even the application of the low-P fertilizer resulted in excess $\mathrm{P}$, because of the high original $\mathrm{P}$ values. Mineral elements, such as $\mathrm{K}, \mathrm{Ca}$ and $\mathrm{Mg}$ were moderate and similar in both fields. The spring test results were influenced by the precondition of the soil and masked the effect of low-P fertilization in reducing the residual $\mathrm{P}$ concentrations.

The second soil sampling was conducted in October during the winter tea harvest. The soil was more acidic than in the spring, and there were less organic matter and available $\mathrm{P}$. The available $\mathrm{P}$ in the soil of both sites was still high, but there was a significant reduction in available $\mathrm{P}$ in the low-P site. There was a $50.6 \%$ reduction in available $\mathrm{P}$ in the low-P site from spring $(920 \mathrm{mg} / \mathrm{kg})$ to winter (454 $\mathrm{mg} / \mathrm{kg}$ ), which was greater than the reduction at the regular-P site $(32.2 \%) . \mathrm{K}$ and $\mathrm{Ca}$ were present in moderate amounts, but $\mathrm{Mg}$ was less than the recommended concentrations at both sites.

\subsection{Effluent Water Quality}

The results of the effluent water quality analyses for the regular-P and low-P sites are summarized in Table 4. The regular-P site had high conductivity, TDS, COD and total nitrogen (TN), and the low-P site had high average SS and TP concentrations. The SS concentration was affected by site disturbances and had a high variance. The average SS concentrations of the regular-P site and the low-P site were $50.5 \mathrm{mg} / \mathrm{L}$ and $68.0 \mathrm{mg} / \mathrm{L}$, with standard deviations of 63.7 and 24.9, respectively. The results showed high variability on the SS concentration. The test fields were flat and well maintained for tea production, and they were cultivated and fertilized in the same manner. It was assumed that the similar field environment and soil conditions should result in analogous soil erosion and SS concentration. The difference in SS concentration might have been influenced by the transportation processes that occurred in underground drainage instead of from the application of the different fertilizers. The TP concentration also showed high variation. Although the data showed a higher average TP concentration at the low-P site, there was a decreasing trend of TP concentrations (Figure 4). The TP concentration might have been affected by soil preconditions, and the soil quality analysis confirmed this hypothesis. There was an increased amount of available $\mathrm{P}$ in the soil of the low-P site compared to that of the regular-P site at the start of the experiment. In the winter season, however, the available $\mathrm{P}$ in the soil of the low-P site then decreased and became lower than that of the regular-P site. The effluent quality from the low-P site followed the same trend, with a higher initial concentration and lower concentration as the season progressed. The TP concentration in the soil of the regular-P site was unstable and showed no clear trend.

The effluent from the regular-P field had very high TN $(22.5 \mathrm{mg} / \mathrm{L})$. The major constituents of TN are $\mathrm{NO}_{2}-\mathrm{N}$ and $\mathrm{NO}_{3}-\mathrm{N}$. The $\mathrm{NO}_{3}-\mathrm{N}$ concentration was $11.75 \mathrm{mg} / \mathrm{L}$ in the effluent from the regular-P site, which was almost 10-times greater than that from the low-P site. High $\mathrm{NO}_{2}-\mathrm{N}$ and $\mathrm{NO}_{3}-\mathrm{N}_{\text {present }}$ threats to the groundwater and the receiving water bodies. In contrast, the major constituent of TN in the effluent from the low-P site was TKN, which consists of ammonia $\mathrm{N}$ and organic $\mathrm{N}$, and was available for biological utilization. However, the mechanism by which the $\mathrm{P}$ fertilizers influenced the $\mathrm{N}$ contents in the soil or effluents was unclear. Additional research and discussions are required to resolve this issue. 
Table 4. The quality of effluents from tea plantations with different experimental fertilizer treatments. DO, dissolved oxygen; TDS, total dissolved solids; COD, chemical oxygen demand; SS, suspended solids; TP, total phosphorus; TKN, total Kjeldahl nitrogen.

\begin{tabular}{ccccccccccccc}
\hline \multirow{2}{*}{ Treatment } & & $\begin{array}{c}\text { DO } \\
(\mathbf{m g} / \mathbf{L})\end{array}$ & $\mathbf{p H}$ & Conductivity & $\begin{array}{c}\text { TDS } \\
(\mathbf{m g} / \mathbf{L})\end{array}$ & $\begin{array}{c}\text { COD } \\
(\mathbf{m g} / \mathbf{L})\end{array}$ & $\begin{array}{c}\text { SS } \\
(\mathbf{m g} / \mathbf{L})\end{array}$ & $\begin{array}{c}\text { TP } \\
(\mathbf{m g} / \mathbf{L})\end{array}$ & $\begin{array}{c}\text { TKN } \\
(\mathbf{m g} / \mathbf{L})\end{array}$ & $\begin{array}{c}\mathbf{N O}_{2}-\mathbf{N} \\
(\mathbf{m g} / \mathbf{L})\end{array}$ & $\begin{array}{c}\mathbf{N O}_{3}-\mathbf{N} \\
(\mathbf{m g} / \mathbf{L})\end{array}$ & $\begin{array}{c}\text { TN } \\
(\mathbf{m g} / \mathbf{L})\end{array}$ \\
\hline \multirow{2}{*}{ Regular-P P } & Average & 9.84 & 7.45 & 198.98 & 143.22 & 78.20 & 50.50 & 0.45 & 5.40 & 7.16 & 11.75 & 22.52 \\
\cline { 2 - 13 } & SD & 4.17 & 0.72 & 139.56 & 74.70 & 88.10 & 63.75 & 0.40 & 8.49 & 11.63 & 10.56 & 20.27 \\
\hline \multirow{2}{*}{ Low-P } & Average & 13.47 & 6.98 & 176.88 & 128.14 & 54.73 & 68.00 & 0.88 & 6.53 & 0.54 & 1.40 & 8.47 \\
\cline { 2 - 12 } & SD & 10.60 & 0.49 & 126.88 & 84.47 & 27.23 & 24.92 & 0.70 & 4.75 & 0.79 & 1.02 & 5.50 \\
\hline
\end{tabular}

Figure 4. The TP concentration of effluents in each sample. There is a decrease in TP concentration in the effluent from the low-P site and an unstable distribution of TP concentration in the effluent from the regular-P site.

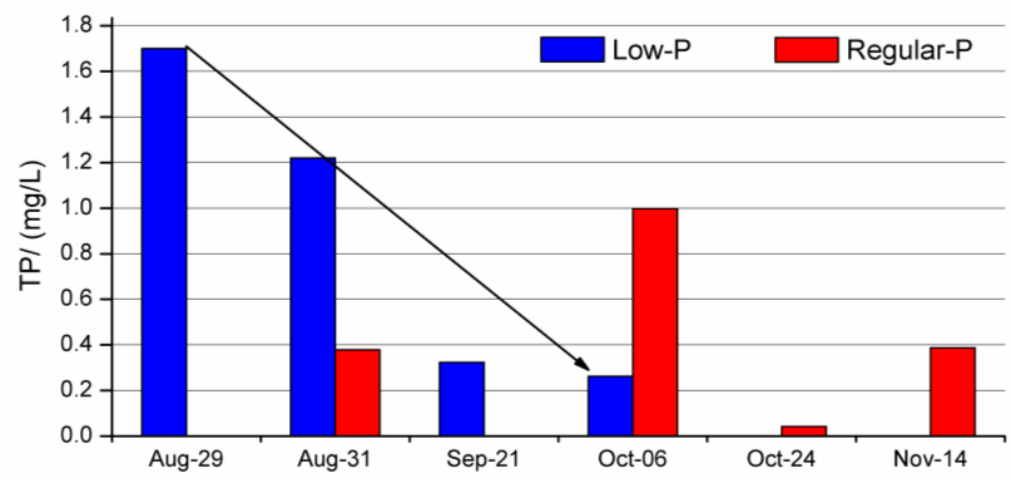

\subsection{Tea Quality}

The appearance and yield of harvested tea leaves were not significantly different in the two fields, but the thickness of the tea leaves and the number of tea buds were significantly different in the winter season (Table 5). The thickness of the tea leaves and the amount of harvested tea from a fixed sampling area in the low-P field were lower than those in the regular-P field, which was most likely a result of insect damage to the low-P field in the winter. There was no difference in the general appearance of the harvested tea leaves from the two fields.

Table 5. Agricultural characteristics of the tea buds and leaves with different fertilizer treatments.

\begin{tabular}{|c|c|c|c|c|c|c|}
\hline Treatment & $\begin{array}{c}\text { Leaf length } \\
(\mathrm{mm})\end{array}$ & $\begin{array}{c}\text { Leaf width } \\
(\mathrm{mm})\end{array}$ & $\begin{array}{c}\text { Internode length } \\
(\mathrm{mm})\end{array}$ & $\begin{array}{c}\text { Leaf thickness } \\
(\mu \mathrm{m})\end{array}$ & $\begin{array}{c}\text { Number of tea buds from } \\
\text { a standard area (buds) }\end{array}$ & $\begin{array}{c}\text { Weight of } 100 \\
\text { tea buds (g) }\end{array}$ \\
\hline \multicolumn{7}{|c|}{ Spring } \\
\hline Regular-P & $69.4 \pm 2.1^{\mathrm{a}}$ & $33.1 \pm 0.8^{a}$ & $32.2 \pm 1.5^{\mathrm{a}}$ & $27.8 \pm 0.4^{a}$ & $45.6 \pm 1.4^{\mathrm{a}}$ & $52.2 \pm 2.7^{\mathrm{a}}$ \\
\hline Low-P & $66.8 \pm 1.9^{\mathrm{a}}$ & $32.6 \pm 0.8^{\mathrm{a}}$ & $29.0 \pm 1.0^{\mathrm{a}}$ & $27.5 \pm 0.4^{\mathrm{a}}$ & $42.0 \pm 3.9^{\mathrm{a}}$ & $53.7 \pm 2.6^{\mathrm{a}}$ \\
\hline \multicolumn{7}{|c|}{ Winter } \\
\hline Regular-P & $61.2 \pm 1.1^{\mathrm{a}}$ & $31.2 \pm 0.5^{\mathrm{a}}$ & $24.7 \pm 0.8^{a}$ & $26.7 \pm 0.3^{\mathrm{a}}$ & $43.0 \pm 2.8^{\mathrm{a}}$ & $54.4 \pm 1.5^{\mathrm{a}}$ \\
\hline Low-P & $58.4 \pm 1.1^{\mathrm{a}}$ & $31.2 \pm 0.5^{\mathrm{a}}$ & $25.4 \pm 0.8^{\mathrm{a}}$ & $25.3 \pm 0.2^{b}$ & $27.2 \pm 2.9^{b}$ & $53.8 \pm 1.9^{\mathrm{a}}$ \\
\hline
\end{tabular}

Note: Mean \pm standard deviation. Means within each column followed by different letters are significantly different at $p<0.05$ using an unpaired $t$-test for each season. "a" and "b" means that "a" is statistically higher than "b". Both "a" means the two treatments are not significantly different. 
Table 6 shows the characteristics of the harvested tea leaves and buds from the two fields. There were few significant differences between the leaves and buds from the two fields in either the spring or winter season. The elements contained in the tea leaves were approximately the same, which indicates that excessive fertilization does not help to increase plant nutrient uptake. The P concentration in the tea leaves was $3.1 \mathrm{~g} / \mathrm{kg}$ in spring and $3.6 \mathrm{~g} / \mathrm{kg}$ in winter.

Table 6. Element contents of tea leaves with different fertilizer treatments.

\begin{tabular}{|c|c|c|c|c|c|}
\hline Treatment & $\mathbf{N}(\mathbf{g} / \mathbf{k g})$ & $P(g / k g)$ & K (g/kg) & Ca (g/kg) & $\operatorname{Mg}(\mathrm{g} / \mathrm{kg})$ \\
\hline \multicolumn{6}{|c|}{ Spring } \\
\hline Regular-P & $28.7 \pm 0.8^{\mathrm{b}}$ & $3.1 \pm 0.1^{\mathrm{a}}$ & $11.6 \pm 0.1^{\mathrm{a}}$ & $2.9 \pm 0.1^{\mathrm{a}}$ & $1.4 \pm 0.0^{\mathrm{a}}$ \\
\hline Low-P & $36.9 \pm 0.7^{\mathrm{a}}$ & $3.1 \pm 0.1^{\mathrm{a}}$ & $11.8 \pm 0.1^{\mathrm{a}}$ & $3.1 \pm 0.0^{\mathrm{a}}$ & $1.4 \pm 0.0^{\mathrm{a}}$ \\
\hline \multicolumn{6}{|c|}{ Winter } \\
\hline Regular-P & $43.0 \pm 0.3^{a}$ & $3.6 \pm 0.0^{\mathrm{a}}$ & $26.1 \pm 1.2^{\mathrm{a}}$ & $2.4 \pm 0.0^{\mathrm{b}}$ & $1.6 \pm 0.0^{\mathrm{a}}$ \\
\hline Low-P & $42.2 \pm 0.2^{\mathrm{a}}$ & $3.6 \pm 0.0^{\mathrm{a}}$ & $25.6 \pm 2.4^{\mathrm{a}}$ & $2.7 \pm 0.0^{\mathrm{a}}$ & $1.6 \pm 0.0^{\mathrm{a}}$ \\
\hline Treatment & $\mathrm{Fe}(\mathrm{mg} / \mathrm{kg})$ & $\mathrm{Mn}(\mathrm{mg} / \mathrm{kg})$ & $\mathrm{Cu}(\mathrm{mg} / \mathrm{kg})$ & $\mathrm{Al}(\mathrm{mg} / \mathrm{kg})$ & $\mathrm{Zn}(\mathrm{mg} / \mathrm{kg})$ \\
\hline \multicolumn{6}{|c|}{ Spring } \\
\hline Regular-P & $218.6 \pm 6.8^{\mathrm{a}}$ & $720.0 \pm 5.5^{b}$ & $13.1 \pm 1.5^{\mathrm{a}}$ & $720.3 \pm 5.7^{\mathrm{a}}$ & $29.4 \pm 1.7^{\mathrm{a}}$ \\
\hline Low-P & $118.4 \pm 1.5^{\mathrm{b}}$ & $796.0 \pm 3.8^{\mathrm{a}}$ & $11.3 \pm 0.2^{\mathrm{a}}$ & $544.0 \pm 3.7^{\mathrm{b}}$ & $24.2 \pm 0.6^{\mathrm{a}}$ \\
\hline \multicolumn{6}{|c|}{ Winter } \\
\hline Regular-P & $112.8 \pm 1.7^{\mathrm{a}}$ & $787.3 \pm 14.3^{\mathrm{a}}$ & $7.0 \pm 0.1^{\mathrm{a}}$ & - & $20.3 \pm 0.3^{\mathrm{a}}$ \\
\hline Low-P & $106.9 \pm 1.9^{\mathrm{a}}$ & $767.5 \pm 9.6^{\mathrm{a}}$ & $6.7 \pm 0.2^{\mathrm{a}}$ & - & $17.3 \pm 0.4^{\mathrm{b}}$ \\
\hline
\end{tabular}

We invited three local tea sensory evaluation experts to judge the quality of the tea, including the appearance of the treated tea leaves and drinking quality. The total quality scores of the tea from the low-P field were higher than those from the regular-P field in both the spring and winter seasons (Table 7). The smell and taste of the spring tea were judged to be better, whereas almost all of the drinking quality factors of the winter tea from the low-P field received higher scores. The score for appearance was lower for the low-P tea, but this may have been influenced by the insect infestation. Therefore, the application of low-P fertilizers can improve tea quality on tea plantations that already have sufficient available $\mathrm{P}$ in the soil, and excessive fertilization did not improve the tea quality. Figure 5 is a photograph of the tea sensory evaluation setting.

We analyzed the quality of brewed tea based on the theanine, caffeine, catechin and total catechin contents to determine why the tea from the low-P field received higher taste scores than the from the regular-P field. These four compounds affect tea quality, with theanine helping to sweeten the tea and catechin contributing to bitterness. The results of the analysis are shown in Table 8. For spring tea, only the theanine content of the tea that was grown in the low-P and regular-P fields differed significantly. None of the compounds differed significantly in the winter tea. However, the higher 
theanine content of the tea from the low-P field might emphasize the sweetness, which resulted in a higher tea quality score for tea from the low-P field.

Table 7. The results of sensory evaluations of the manufactured tea (graded by three tea experts, with a total score of 100).

\begin{tabular}{cccccc}
\hline Treatment & $\begin{array}{c}\text { Appearance } \\
\mathbf{( 2 0 \% )}\end{array}$ & $\begin{array}{c}\text { Color of liquid } \\
\mathbf{( 2 0 \% )}\end{array}$ & $\begin{array}{c}\text { Aroma } \\
\mathbf{( 3 0 \% )}\end{array}$ & $\begin{array}{c}\text { Taste } \\
\mathbf{( 3 0 \% )}\end{array}$ & $\begin{array}{c}\text { Total score } \\
\mathbf{( 1 0 0 \% )}\end{array}$ \\
\hline \multicolumn{5}{c}{ Spring } \\
\hline Regular-P & 11.0 & 14.0 & 21.0 & 21.0 & 67.0 \\
\hline Low-P & 11.0 & 14.0 & 25.5 & 25.5 & 76.0 \\
\hline \multicolumn{7}{c}{ Winter } \\
\hline Regular-P & 15.3 & 13.3 & 23.3 & 22.3 & 74.3 \\
\hline Low-P & 14.7 & 14.7 & 24.0 & 23.0 & 76.3 \\
\hline
\end{tabular}

Figure 5. Photograph of the tea sensory evaluation setting. Evaluations included the appearance of the manufactured tea, the color of the liquid and the aroma and taste of the drinking tea.

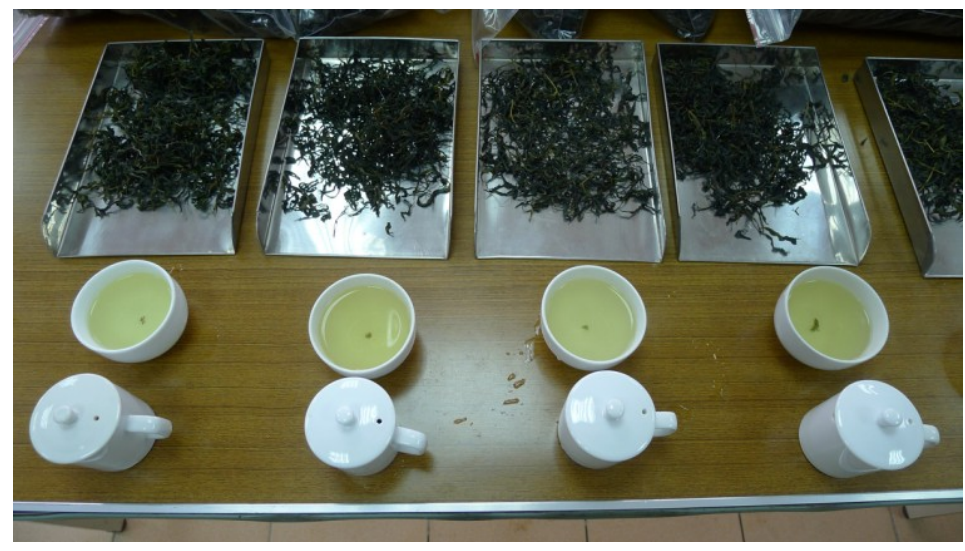

Table 8. The results of a chemical analysis of the manufactured tea.

\begin{tabular}{|c|c|c|c|c|}
\hline Treatment & Theanine (mg/g) & Caffeine (mg/g) & Catechin (mg/g) & Total catechin (mg/g) \\
\hline \multicolumn{5}{|c|}{ Spring } \\
\hline Regular-P & $9.26 \pm 0.09^{b}$ & $15.55 \pm 0.44^{\mathrm{a}}$ & $23.34 \pm 0.53^{\mathrm{a}}$ & $96.44 \pm 1.59^{\mathrm{a}}$ \\
\hline Low-P & $10.76 \pm 0.00^{\mathrm{a}}$ & $17.01 \pm 0.42^{a}$ & $24.75 \pm 1.22^{a}$ & $95.16 \pm 2.51^{\mathrm{a}}$ \\
\hline \multicolumn{5}{|c|}{ Winter } \\
\hline Regular-P & $6.55 \pm 0.31^{\mathrm{a}}$ & $14.98 \pm 0.67^{\mathrm{a}}$ & $21.54 \pm 1.44^{\mathrm{a}}$ & $46.00 \pm 2.26^{\mathrm{a}}$ \\
\hline Low-P & $7.49 \pm 0.23^{\mathrm{a}}$ & $15.13 \pm 0.24^{\mathrm{a}}$ & $19.49 \pm 0.42^{\mathrm{a}}$ & $43.15 \pm 0.50^{\mathrm{a}}$ \\
\hline
\end{tabular}

Note: Mean \pm standard deviation. Means within each column that are followed by the different letters are significantly different at $p<0.05$ using an unpaired $t$-test for each season. "a" and "b" means that "a" is statistically higher than "b". Both "a" means the two treatments are not significantly different.

\section{Conclusions}

Excessive fertilization does not improve plant growth, but threatens soil and water quality. Taipei Feitsui Reservoir Administration in Taiwan attempts to preserve good water quality by promoting 
low-P fertilizers as a new BMP. This study demonstrated the results of applying low-P and regular-P fertilizers and concluded that low-P fertilizers help to improve the quality of the effluents and brewed tea at the study sites. There were no significant differences in the agricultural characteristics and yield between the low-P and regular-P fields. The taste of the manufactured tea from the low-P field was judged to be better, because the brewed tea contained more theanine. Although this study did not focus on $\mathrm{N}$, the extremely high TN concentration of effluents from the regular-P field should be noted for future studies.

The test fields were located on existing tea plantations and have been cultivated and harvested for many years. Therefore, the precondition of the soil influenced the study results. The available $\mathrm{P}$ in the original soil of the low-P test field was already enriched, so the low-P fertilizers were sufficient to maintain the tea yield and even improved the tea quality. Low-P fertilizers should be considered as an alternative BMP for specific situations, but they should not be used as a universal BMP for all croplands.

\section{Acknowledgment}

This study was supported by grants from Taipei Feitsui Reservoir Administration. The authors would like to thank Taiwan Fertilizer Co., Ltd., for producing the new low-P compound fertilizers.

\section{Author Contributions}

All authors were involved in designing and discussing the study. Chi-Feng Chen drafted and finalized the manuscript and performed the effluent analysis. Chih-Yi Hu managed the test fields, performed tea analysis and wrote part of the manuscript. Ming-Lone Liou initiated the study idea. Chia-Chang Wu, Yen-Shuo Su and Chien-Ju Liu performed and analyzed the soil analysis and tea analysis. All authors have read and approved the final manuscript.

\section{Conflicts of Interest}

The authors declare no conflict of interest.

\section{References}

1. Frossard, E.; Condron, L.M.; Oberson, A.; Sinaj, S.; Fardeau, J.C. Process governing phosphorus availability in temperate soils. J. Environ. Qual. 2000, 29, 15-23.

2. Sainju, U.M.; Whitehead, W.F.; Singh, B.P. Agricultural management practices to sustain crop yields and improve soil and environmental quality. Sci. World J. 2003, 3, 768-789.

3. Hirono, Y.; Watanabe, I.; Nonaka, K. Trends in water quality around an intensive tea-growing area in Shizuoka, Japan. Soil Sci. Plant Nutr. 2009, 55, 783-792.

4. Liu, Z.; Yang, J.; Yang, Z.; Zou, J. Effects of rainfall and fertilizer types on nitrogen and phosphorus concentrations in surface runoff from subtropical tea fields in Zhejiang, China. Nutr. Cycle Agoroecosyst. 2012, 93, 297-307. 
5. Maghanga, J.K.; Kituyi, J.L.; Kisinyo, P.O.; Ngetich, W.K. Impact of nitrogen fertilizer applications on surface water nitrate levels within a Kenyan tea plantation. J. Chem. 2013, doi:10.1155/2013/196516.

6. Kim, M.K.; Seo, M.C.; Kim, M.Y.; Chung, J.B.; Kim, B.J. Estimating nitrogen and phosphorus contents using model integrated in small agricultural watersheds. J. Environ. Sci. Health Part A 2004, 39, 1833-1842.

7. Chang, S.P.; Chuang, S.M. Eutrophication study of twenty reservoirs in Taiwan. Water Sci. Technol. 2001, 44, 19-26.

8. Zehetner, F.; Vemuri, N.L.; Huh, C.A.; Kao, S.J.; Hsu, S.C.; Huang, J.C.; Chen, Z.S. Soil and phosphorus redistribution along a steep tea plantation in the Feitsui reservoir catchment of northern Taiwan. Soil Sci. Plant Nutr. 2008, 54, 618-626.

9. Chang, Y.C. The Effect of Fertilizing Tea Plantation to Peishih River. Master's Thesis, National Taiwan University, Taipei, Taiwan, 2009.

10. Wu, C.W. Developing a nutrient TMDL program in Feitsui Reservoir Watershed. Master's Thesis, National Taipei University of Technology, Taipei, Taiwan, 2010.

11. Zheng, Z.M.; Zhang, T.Q. Soil Phosphorus Tests and Transformation Analysis to Quantify Plant Availability: A Review. In Soil Fertility Improvement and Integrated Nutrient Management-A Global Perspective; Whalen, J.K., Ed.; In Tech: Winchester, UK, 2012; pp. 19-36.

12. Blevins, R.L; Frye, W.W.; Baldwin, P.L.; Robertson, S.D. Tillage effects on sediment and soluble nutrient losses from a Maury silt loam soil. J. Environ. Qual. 1990, 19, 683-686.

13. Sharpley, A.N.; Smith, S.J. Wheat tillage and water quality in the Southern plains. Soil Tillage Res. 1994, 30, 33-48.

14. Knudsen, D.; Peterson, G.A.; Pratt, P.F. Lithium, Sodium and Potassium. In Methods of Soil Analysis Part 2. Chemical and Microbiological Properties; Page, A.L., Ed.; American Society of Agronomy: Madison, WI, USA, 1982; pp. 225-238.

15. Recommended Chemical Soil Test Procedures for the North Central Region. Available online: http://infohouse.p2ric.org/ref/17/16690.pdf (accessed on 1 October 2014).

16. Bremner, J.M. Total Nitrogen, Inorganic Forms of Nitrogen, Organic Forms of Nitrogen. In Method of Soil Analysis Part 2; Black, C.A., Ed.; American Society of Agronomy: Madison, WI, USA, 1965; pp. 1149-1178.

(C) 2014 by the authors; licensee MDPI, Basel, Switzerland. This article is an open access article distributed under the terms and conditions of the Creative Commons Attribution license (http://creativecommons.org/licenses/by/4.0/). 